\title{
確率的切り替えを伴う ARX モデルのパラメータ推定法
}

\author{
山田直 幸*·鈴 木 達 也*・稲 垣 伸 吉* \\ On the Parameter Estimation of Stochastic Switched ARX Model \\ Naoyuki YAMADA*, Tatsuya SuzUKI* and Shinkichi INAGAKI*
}

\begin{abstract}
This paper presents a parameter identification technique for a stochastic switched ARX model. The developed algorithm can be regarded as a natural extension of the learning algorithm for Hidden Markov Model (HMM), which is based on the EM algorithm. The results of the estimation of the parameter in the ARX model at each discrete state can be comprehended as a solution for the weighted least mean square estimation problem. The usefulness of the proposed technique is verified through some numerical experiments for the switched impedance model with and without existence of the modelling error.
\end{abstract}

Key Words: hybrid system, ARX model, HMM

\section{1.はじめに}

微分 (差分) 方程式と論理が混在したシステムはハイブ リッドシステムと呼ばれ，ここ数年システム制御や計算機 科学の分野で多くの注目を集めている ${ }^{1)}$. 中でもハイブリッ ドシステムのパラメータ推定問題はヒトの行動解析 ${ }^{2)}$ や故 障診断，さらにはシステムバイオロジーなど，応用範囲も広 く，今後さまざまな分野で用いられることが予想される。

ハイブリッドシステムは大きく分けて, 離散状態間の遷移 が確定的（論理的）に規定されているハイブリッドシステム と, 離散状態間の遷移が確率で規定されているハイブリッド システムとに分けられ，それぞれにおいて，あるクラスに対 していくつかのパラメータ推定法が提案されている. 前者の 確定的なハイブリッドシステムにおいては, データクラス夕 リングとサポートベクタマシンに基づく方法 ${ }^{3)}$ や, 論理条 件を不等式に変換し，混合整数計画法に帰着する方法 ${ }^{4)}$ どが提案されている. 一方, 後者の確率的なハイブリッドシ ステムにおいては，隠れマルコフモデル（HMM）の拡張, という形で取り扱われる形が多く，通常は EMアルゴリズ ムがパラメー夕推定の出発点となる ${ }^{5), 6)}$.これらの手法に おいては, 各離散状態に連続のダイナミクスが割り当てら れ，そのダイナミクスを通して出力信号が観測される点が従 来の HMM との大きな相違点となっている.しかしながら， 文献 ${ }^{5)}$,6) で示される枠組みでは, システムへの入力を陽に 考慮に入れていないことから, 入出力関係をモデル化するシ

* 名古屋大学大学院工学研究科 名古屋市千種区不老町

* Graduate School of Engineering, Nagoya University, Chikusa-ku, Nagoya

(Received February 4, 2005)

(Revised May 27, 2005)
ステム同定，という観点から見た場合，利便性にかける． そこで本論文では, HMM の各離散状態にシステム同定で 用いられる ARX モデルを割り当てた確率的なハイブリッド システム表現（Stochastic Switched ARX モデル）を対象 とし, 入出力データから Stochastic Switched ARX モデル のパラメー夕を推定するアルゴリズムを提案する。そして， 提案するパラメー夕推定法を切り替えを伴うインピーダン スモデルの推定に応用する．切り替えを伴うインピーダンス モデルは人間の作業スキルの数理モデルとしてしばしば取

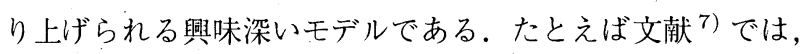
インピーダンスパラメータを出カシンボルとする HMM を 用いて人間の技能を表現し，それをロボットの制御に用いる ことを提案している。しかしながら，文献7)ではインピー ダンスパラメータの同定と HMM のパラメータ推定は独立 して行なわれており，得られたパラメータ群の信頼性には疑 問があった。これに対して，本論文で提案するパラメー夕推 定法を用いれば，これらは同一の理論規範のもと同時に最適 化されるため, より信頼度の高いパラメータ群が得られるこ とになる。

本論文ではまず 2 章で, ARX モデルと HMM について 述べ，3章でそれらを融合した Stochastic Switched ARX モデルの構成について述べる。 そして 4 章では, Stochastic Switched ARX モデルのパラメー夕を推定するアルゴリズ ムを述へ，結果として得られる各離散状態における ARX モ デル中のパラメータは, 該当する離散状態に滞在する確率を 重みとした最小二乗解となることを示す．最後に 5 章では， 提案するアルゴリズムを, 切り替えが生じる機械インピーダ ンスモデルに適用し，その有用性を示す。 


\section{ARX モデルと HMM}

ここでは，確率的な切り替えを伴う ARX モデルについて 述べる準備として, ARX モデルと, 離散的状態遷移を表わ すHMMについて述べる。

\subsection{ARX モデル}

システム同定に扔ける数学モデルとして，ある時点での 出力は, 多くの過去の時点での入出力に依存するという (1) 式のような線形差分方程式を考える.

$$
\begin{aligned}
y_{t}= & c_{1} y_{t-1}+c_{2} y_{t-2}+\cdots+c_{n} y_{t-n} \\
& +d_{0} u_{t}+d_{1} u_{t-1}+\cdots+d_{m} u_{t-m}+e_{t}
\end{aligned}
$$

ここで, $y_{t}$ は時刻 $t$ でのシステムの出力, $u_{t}$ は時刻 $t$ でのシステムへの入力, $n, m$ はそれぞれ ARX モデルにお ける過去の出力数と入力数, $c_{1}, c_{2}, \cdots, c_{n}, d_{0}, d_{1}, \cdots, d_{m}$ は パラメータを表わす. また $t-n<0$ のとき $y_{t-n}=0$, $t-m<0$ のとき $u_{t-m}=0$ とする.

$e_{t}$ は式誤差と呼ばれるもので, 平均 0 , 分散 $\sigma$ のガウス 分布に従う白色雑音と仮定する。

また，つぎのようにパラメータべクトル $\boldsymbol{\theta}$ とデータベク トル $\psi_{t}$ を定義すると，

$$
\begin{aligned}
\boldsymbol{\theta} & =\left(c_{1}, c_{2}, \cdots, c_{n}, d_{0}, d_{1}, \cdots, d_{m}\right)^{T} \\
\boldsymbol{\psi}_{t} & =\left(y_{t-1}, y_{t-2}, \cdots, y_{t-n}, u_{t}, u_{t-1}, \cdots, u_{t-m}\right)^{T}(3)
\end{aligned}
$$

(1) 式は,

$$
y_{t}=\boldsymbol{\psi}_{t}^{T} \boldsymbol{\theta}+e_{t}
$$

となる。一方，つぎの既約なシフトオペレー夕 $q$ の多項式

$$
\begin{aligned}
& A(q)=1+c_{1} q^{-1}+\cdots+c_{n} q^{-n} \\
& B(q)=d_{0}+d_{1} q^{-1}+\cdots+d_{m} q^{-m}
\end{aligned}
$$

を導入すると (1) 式は，

$$
\begin{aligned}
A(q) y_{t} & =B(q) u(t)+e_{t}, \\
y_{t} & =\frac{B(q)}{A(q)} u(t)+\frac{1}{A(q)} e_{t}
\end{aligned}
$$

と書ける。このように記述されるモデルを ARX(AutoRegressie eXogeneous) モデルといい, システム同定によ 〈用いられる数学モデルのひとつである.ARX モデルのブ ロック線図をFig. 1 に示す.

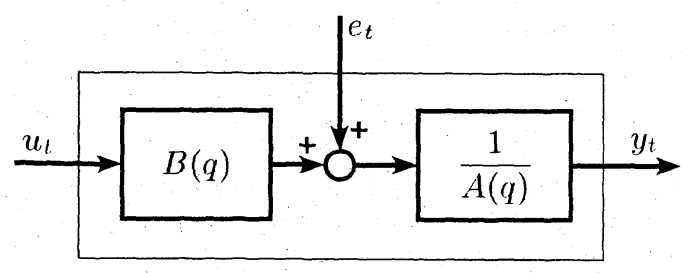

Fig. 1 ARX model

\section{2 隠れマルコフモデル (Hidden Markov Model : HMM)}

隠れマルコフモデルとは, マルコフモデルでの「一つの状 態が唯一のシンボルを出力する」という仮定を, 離散状態の 削隇を目的として,「おのおのの状態で，任意の記号を，あ る決まった確率で出力する」としたモデルである.

HMM は, 以下のパラメータ群で表わされ，また Fig. 2 の ようにグラフイカルに表現される（状態数は 3 としている）.

・離散状態の集合 $S\left[=S_{i},(i=0,1, \cdots, N)\right]$

- 出カシンボルの集合 $V\left[=v_{k},(k=0,1, \cdots, M)\right]$

- $a_{i j}$ : 状態遷移確率 $(i=0,1, \cdots, N ; j=0,1, \cdots, N)$, $a_{i j}$ は状態 $S_{i}$ から $S_{j}$ への遷移確率

- $b_{i}\left(v_{k}\right)$ : 各状態におけるシンボル生起確率 $(i=0,1, \cdots$, $N ; k=0,1, \cdots, M), b_{i}\left(v_{k}\right)$ は状態 $S_{i}$ で出力 シンボル $v_{k}$ を出力する確率

- $\pi_{i}$ : 初期状態確率 $(i=0,1, \cdots, N), \pi_{i}$ は時刻 $t=0$ で 状態 $S_{i}$ をとる確率

ここで, $N+1$ は離散状態の数で, $M+1$ は出力シンボ ルの数である。

HMM では, 状態が時刻ごとに状態遷移確率 $a_{i j}$ に従って 遷移し, 各状態 $S_{i}$ におけるシンボル生起確率 $b_{i}\left(v_{k}\right)$ に従っ てシンボル $v_{k}$ を出力する，以上のように HMMは，遷移 と出力を繰り返すことで, 時系列デー夕を生成する.

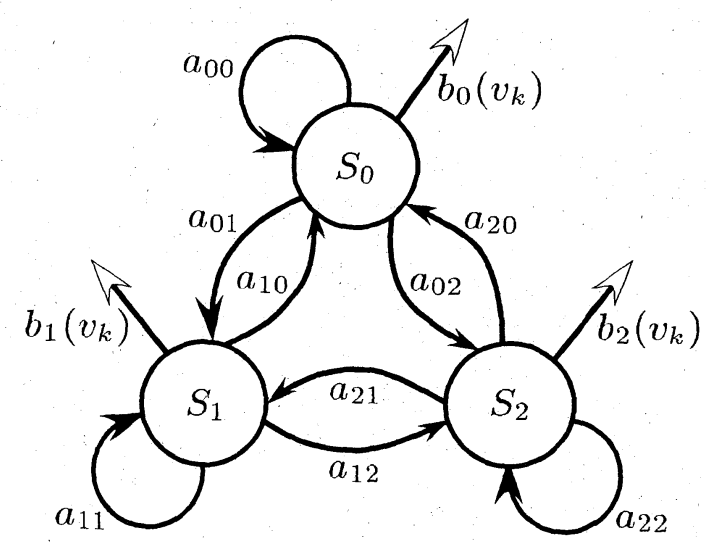

Fig. 2 HMM (3states)

\subsection{HMM $の$ 基本問題}

HMMには，3つの基本問題があり，それぞれに対して解 を求めるアルゴリズムが確立されている。ここで, $o_{t}(\in V)$ は時刻 $t$ での出力シンボル, $s_{t}(\in S)$ は時刻 $t$ での状態とす る. 以下に 3 つの基本問題を示す.

\section{評価問題}

特定のモデルパラメータ $\lambda=\left(\pi_{i}, a_{i j}, b_{i}\left(v_{k}\right)\right)$ が与えられ たとする．評価問題とは，そのモデルから特定の出力シンボ ル系列 $\boldsymbol{O}=\left(o_{0}, o_{1}, \cdots, o_{t}, \cdots, o_{T}\right)$ が観測される確率を求 める問題である。これは Forward アルゴリズムにより求め ることが出来る。 


\section{学習問題}

特定の出力シンボル系列 $\boldsymbol{O}=\left(o_{0}, o_{1}, \cdots, o_{t}, \cdots, o_{T}\right)$ が 与えられたとする. 学習問題とは, 与えられた出力シンボ ル系列を出力する確率が最も高くなるように，モデルパラ メータ $\lambda=\left(\pi_{i}, a_{i j}, b_{i}\left(v_{k}\right)\right)$ を推定する問題である.これは, $\mathrm{EM}$ アルゴリズムに基づいた最尤推定法により求めることが 出来る.

\section{復号問題}

特定のモデルパラメータ $\lambda=\left(\pi_{i}, a_{i j}, b_{i}\left(v_{k}\right)\right)$ と特定の出 カシンボル系列 $\boldsymbol{O}=\left(o_{0}, o_{1}, \cdots, o_{t}, \cdots, o_{T}\right)$ が与えられた とする. 復号問題とは, そのモデルから, 与えられた出力シ ンボル系列が生成される一番もっともらしい状態遷移系列 $\boldsymbol{s}=\left(s_{0}, s_{1}, \cdots, s_{t}, \cdots, s_{T}\right)$ を推定する問題である.これは, Viterbi アルゴリズムにより求めることが出来る.

\section{Stochastic Switched ARX モ゙デル}

ここでは 2 節で述べた，ARX モデルと HMM を融合した Stochastic Switched ARX モデルについて述べる。

Fig. 3 に示すように，ARX モデルで表現された入出力関 倸が，ある遷移確率に従って異なる ARX モデルに遷移する システムを考える．以下これを Stochastic Switched ARX (SS-ARX と略記) ‘モデルと呼ぶことにする，また，各離散 状態 $S_{i}$ での ARX モデルのパラメー夕は，添え字 $i$ をけ て表わすこととする。

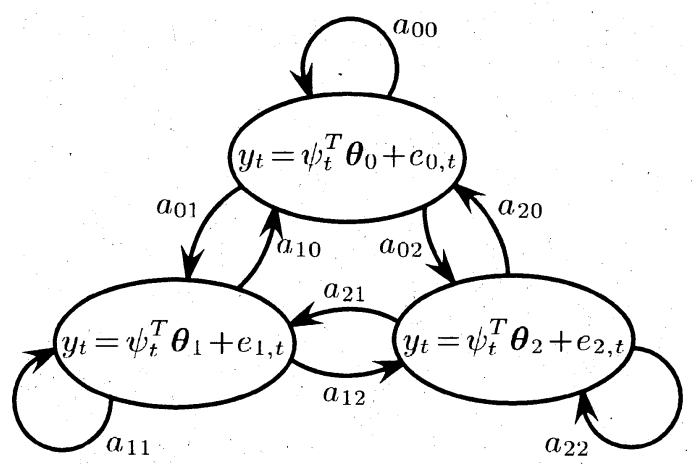

Fig. 3 SS-ARX Model (3states)

\subsection{SS-ARX モデルのパラメータ}

SS-ARX モデルのパラメータを以下のように定義する.

- 離散状態の集合 $S\left[=S_{\boldsymbol{i}},(i=0,1, \cdots, N)\right]$

- $a_{i j}$ : 状態遷移確率 $(i=0,1, \cdots, N ; j=0,1, \cdots, N)$, $a_{i j}$ は状態 $S_{i}$ 加 $S_{j}$ への遷移確率

- $\pi_{i}$ : 初期状態確率 $(i=0,1, \cdots, N), \pi_{i}$ は時刻 $t=0$ で, 状態 $S_{i}$ をとる確率

- $\boldsymbol{\theta}_{i}$ : 各離散状態 $S_{i}$ での $\mathrm{ARX}$ モデルのパラメータベク トル $(i=0,1,2, \cdots, N)$

- $\sigma_{i}$ : 各離散状態 $S_{i}$ に割り当てられた ARX モデルの 式誤差を表わすガウス分布の分散 $(i=0,1,2, \cdots$, $N)$
ここで，N+1 は離散状態の数である。

\section{$3.2 \mathrm{SS}-\mathrm{ARX}$ モデルにおける出カジンボルの定義}

後に SS-ARX モデルのパラメータの最尤推定を行なう準 備として, SS-ARX モデルの時刻 $t$ での観測シシボル $o_{t}$ と, 各離散状態 $S_{i}$ における観測シンボル $o_{t}$ の生起確率 $b_{i}\left(o_{t}\right)$ を定義する。

まず，時刻 $t$ での観測シンボル $o_{t}$ を，各離散状態 $S_{i}$ で の ARX モデルの出力 $y_{t}$ とデータベクトル $\psi_{t}$ を用いて, $o_{t}=\left(y_{t}, \boldsymbol{\psi}_{t}\right)$ と定める.つぎに, 観測シンボル $o_{t}$ の生起確 率 $b_{i}\left(o_{t}\right)$ を，つぎのように与える.

まず，(4)式より，各離散状態における式誤差は次式で与 えられる。

$$
e_{i, t}=y_{t}-\boldsymbol{\psi}_{t}^{T} \boldsymbol{\theta}_{i} .
$$

また，式誤差に対する仮定より，式誤差の確率分布は，

$$
P\left(e_{i, t}\right)=\frac{1}{\sqrt{2 \pi} \sigma_{i}} \exp \left\{-\frac{e_{i, t}^{2}}{2 \sigma_{i}^{2}}\right\}
$$

で与えられる。したがって， $\boldsymbol{\theta}_{i}$ が与えられたとき，観測シ ンボル $o_{t}=\left(y_{t}, \boldsymbol{\psi}_{t}\right)$ が離散状態 $S_{i}$ で観測される確率，す なわち, 状態 $S_{i}$ での観測シンボル $o_{t}$ の生起確率 $b_{i}\left(o_{t}\right)$ は 次式で与えられる。

$$
b_{i}\left(o_{t}\right)=\frac{1}{\sqrt{2 \pi} \sigma_{i}} \exp \left\{-\frac{\left(\boldsymbol{\psi}_{t}^{T} \boldsymbol{\theta}_{i}-y_{t}\right)^{2}}{2 \sigma_{i}^{2}}\right\} .
$$

これらを定義することで，SS-ARX モデルと HMM を 対応付けることができ, 出力確率が連続な密度関数で表わ される連続型 HMM と同様に，HMM の基本アルゴリズム である，Forwardアルゴリズム，Backword アルゴリズム， Viterbi アルゴリズムを導出することができる.

\section{4. パラメータの最尤推定}

ここでは，EMアルゴリズムに基づいて，観測されたシン ボル系列から SS-ARX モデル中のパラメータを推定する問 題 (HMMに拈ける学習問題に相当)を考える。

\section{$4.1 \mathrm{EM}$ アルゴリズム}

今，SS-ARX モデル中のパラメータを $\lambda$ とし，観測でき ない状態遷移系列を $\boldsymbol{s}=\left(s_{0}, s_{1}, \cdots, s_{t}, \cdots, s_{T}\right)$ ，観測でき る出力シンボル系列を $\boldsymbol{O}=\left(o_{0}, o_{1}, \cdots, o_{t}, \cdots o_{T}\right)$ としたと き, $\boldsymbol{s}, \boldsymbol{O}$ が生起する尤度 $L(\boldsymbol{s}, \boldsymbol{O} ; \lambda)=P(\boldsymbol{s}, \boldsymbol{O} \mid \lambda)$ を，最大 化する $\lambda$ (最尤推定量) を求めることを考える.

この問題は解析的に解くことはできないため, EM アルゴ リズムを用いる。 EM アルゴリズムは，尤度 $L(\boldsymbol{s}, \boldsymbol{O} ; \lambda)=$ $P(\boldsymbol{s}, \boldsymbol{O} \mid \lambda)$ を極大化するアルゴリズムである.

一般に, EMアルゴリズムは次式,

$$
\begin{aligned}
Q\left(\lambda, \lambda^{\prime}\right) & =E\left[\log \left\{P\left(\boldsymbol{s}, \boldsymbol{O} \mid \lambda^{\prime}\right)\right\} \mid \boldsymbol{O}, \lambda\right] \\
& =\sum_{\boldsymbol{s}} P(\boldsymbol{s} \mid \boldsymbol{O}, \lambda) \log \left\{P\left(\boldsymbol{s}, \boldsymbol{O} \mid \lambda^{\prime}\right)\right\}
\end{aligned}
$$

で定義される Q 関数を最大化する $\lambda^{\prime}$ を，

（1）適当な初期パラメー夕 $\lambda$ を定める.

( 2 ) $Q\left(\lambda, \lambda^{\prime}\right)$ を最大化する $\lambda^{\prime}$ を求める. 
（3） $\lambda=\lambda^{\prime}$ として収束するまで（2）を繰り返す.

に従って逐次的に求める方法である.

\section{2 パラメータ推定式の導出}

まず，SS-ARX モデルの Q 関数を求める。更新前の SSARX モデルパラメータ (既知)を $\lambda=\left(\pi_{i}, a_{i j}, \boldsymbol{\theta}_{i}, \sigma_{i}\right)$, 更新後の SS-ARX モデルパラメータ（未知）を $\lambda^{\prime}=$ $\left(\pi_{i}^{\prime}, a_{i j}^{\prime}, \boldsymbol{\theta}^{\prime}{ }_{i}, \sigma_{i}^{\prime}\right)$ とする. (13) 式より,

$$
\begin{aligned}
Q\left(\lambda, \lambda^{\prime}\right) & =\sum_{\boldsymbol{s}} P(\boldsymbol{s} \mid \boldsymbol{O}, \lambda) \log \left\{P\left(\boldsymbol{s}, \boldsymbol{O} \mid \lambda^{\prime}\right)\right\} \\
& =\frac{1}{P(\boldsymbol{O} \mid \lambda)} \sum_{\boldsymbol{s}} P(\boldsymbol{s}, \boldsymbol{O} \mid \lambda) \log \left\{P\left(\boldsymbol{s}, \boldsymbol{O} \mid \lambda^{\prime}\right)\right\}
\end{aligned}
$$

と表わされる．ここで，(15) 式中の $\frac{1}{P(\boldsymbol{O} \mid \lambda)}$ は定数なので, 次式で表わされる $\tilde{Q}\left(\lambda, \lambda^{\prime}\right)$ を最大化すればよい.

$$
\tilde{Q}\left(\lambda, \lambda^{\prime}\right)=\sum_{\boldsymbol{s}} P(\boldsymbol{s}, \boldsymbol{O} \mid \lambda) \log \left\{P\left(\boldsymbol{s}, \boldsymbol{O} \mid \lambda^{\prime}\right)\right\} .
$$

$\tilde{Q}\left(\lambda, \lambda^{\prime}\right)$ を最大化する $\lambda^{\prime}$ を求めるために, $Q$ 関数を以下の ように変形する. HMM パラメー夕が $\lambda$ で, 状態遷移系列 が $\boldsymbol{s}$, 出力系列が $\boldsymbol{O}$ となる確率 $P(\boldsymbol{s}, \boldsymbol{O} \mid \lambda)$ は,

$$
\begin{aligned}
P(\boldsymbol{s}, \boldsymbol{O} \mid \lambda)= & \pi_{s_{0}} b_{s_{0}}\left(o_{0}\right) \times a_{s_{0} s_{1}} b_{s_{1}}\left(o_{1}\right) \\
& \times a_{s_{1} s_{2}} b_{s_{2}}\left(o_{2}\right) \times \cdots \times a_{s_{T-1} s_{T}} b_{s_{T}}\left(o_{T}\right)(17)
\end{aligned}
$$

であるから，(17) 式を(16) 式へ代入し，整理すると，

$$
\tilde{Q}\left(\lambda, \lambda^{\prime}\right)=\tilde{Q}_{1}\left(\lambda, \pi_{i}^{\prime}\right)+\tilde{Q}_{2}\left(\lambda, a_{i j}^{\prime}\right)+\tilde{Q}_{3}\left(\lambda,\left(\boldsymbol{\theta}_{i}^{\prime}, \sigma_{i}^{\prime}\right)\right)
$$

となる、ただし，

$$
\begin{aligned}
\tilde{Q}_{1}\left(\lambda, \pi_{i}^{\prime}\right)= & \sum_{s_{0}=0}^{N} \sum_{s_{1}=0}^{N} \cdots \sum_{s_{T}=0}^{N} \pi_{s_{0}} b_{s_{0}}\left(o_{0}\right) \times a_{s_{0} s_{1}} b_{s_{1}}\left(o_{1}\right) \times \\
& \cdots \times a_{s_{T-1} s_{T}} b_{s_{T}}\left(o_{T}\right) \log \left\{\pi_{s_{0}}^{\prime}\right\}, \quad(19) \\
\tilde{Q}_{2}\left(\lambda, a_{i j}^{\prime}\right)= & \sum_{s_{0}=0}^{N} \sum_{s_{1}=0}^{N} \cdots \sum_{s_{T}=0}^{N} \pi_{s_{0}} b_{s_{0}}\left(o_{0}\right) \times a_{s_{0}, s_{1}} b_{s_{1}}\left(o_{1}\right) \times \\
& \cdots \times a_{s_{T-1} s_{T}} b_{s_{T}}\left(o_{T}\right) \times \sum_{t=1}^{T} \log \left\{a_{s_{t-1} s_{t}}^{\prime}\right\} \\
\tilde{Q}_{3}\left(\lambda,\left(\boldsymbol{\theta}_{i}^{\prime}, \sigma_{i}^{\prime}\right)\right)= & \sum_{s_{0}=0}^{N} \sum_{s_{1}=0}^{N} \ldots \sum_{s_{T}=0}^{N} \pi_{s_{0}} b_{s_{0}}\left(o_{0}\right) \times a_{s_{0} s_{1}} b_{s_{1}}\left(o_{1}\right) \times \\
& \cdots \times a_{s_{T-1} s_{T}} b_{s_{T}}\left(o_{T}\right) \times \sum_{t=0}^{T} \log \left\{b_{s_{l}}^{\prime}\left(o_{t}\right)\right\}
\end{aligned}
$$

である.

つぎに，前向き確率 $\alpha(i, t)$ と，後乃向き確率 $\beta(i, t)$ を以 下のように定義する。

前向き確率 $\alpha(i, t)$ とは，パラメータが $\lambda$ である SS-ARX モデルが, 時刻 $t$ までに出力記号系列 $\boldsymbol{O}=\left(o_{0}, o_{1}, \cdots, o_{t}\right)$ を出力して, 状態 $S_{i}$ に達する $\left(s_{t}=S_{i}\right.$ となる $)$ 確率であ
る.また，後ろ向き確率 $\beta(i, t)$ とは，パラメータが $\lambda$ であ る SS-ARX モデルが，時刻 $t$ で状態 $S_{i}$ から $\left(s_{t}=S_{i}\right.$ か ら ), 出力記号系列 $\boldsymbol{O}=\left(o_{t+1}, o_{t+2}, \cdots, o_{T}\right)$ を出力して, 最終状態に達する確率である。

したがって, 前向き確率 $\alpha(i, t)$ と, 後ろ向き確率 $\beta(i, t)$ は, 次式のように表わされる。

$$
\begin{aligned}
\alpha(i, t)= & \sum_{s_{0}=0}^{N} \sum_{s_{1}=0}^{N} \cdots \sum_{s_{t-1}=0}^{N} \pi_{s_{0}} b_{s_{0}}\left(o_{0}\right) \\
& \times a_{s_{0} s_{1}} b_{s_{1}}\left(o_{1}\right) \times \cdots \times a_{s_{t-1} s_{t}} b_{s_{l}}\left(o_{t}\right), \quad(22) \\
\beta(i, t)= & \sum_{s_{t+1}=0}^{N} \sum_{s_{t+2}=0}^{N} \cdots \sum_{s_{T}=0}^{N} a_{s_{t} s_{t+1}} b_{t+1}\left(o_{t+1}\right) \\
& \times a_{s_{t+1} s_{t+2}} b_{s_{t+2}}\left(o_{t+2}\right) \times \cdots \times a_{s_{T-1} s_{T}} b_{s_{T}}\left(o_{T}\right) .
\end{aligned}
$$

よって, $(19)(20)(21)$ 式は, $(22)(23)$ 式よりつぎのように前 向き確率と，後乃向き確率を使って表わすことができる。

$$
\begin{aligned}
& \tilde{Q}_{1}\left(\lambda, \pi_{i}^{\prime}\right)=\sum_{i=0}^{N} \pi_{i} \log \left\{\pi_{i}^{\prime}\right\} b_{i}\left(o_{0}^{\prime}\right) \beta(i, 0), \\
& \tilde{Q}_{2}\left(\lambda, a_{i j}^{\prime}\right)=\sum_{t=1}^{T} \sum_{i=0}^{N} \sum_{j=0}^{N} \log \left\{a_{i j}^{\prime}\right\} \alpha(i, t-1) a_{i j} b_{i}\left(o_{t}\right) \beta(j, t),
\end{aligned}
$$

$\tilde{Q}_{3}\left(\lambda,\left(\boldsymbol{\theta}_{i}^{\prime}, \sigma_{i}^{\prime}\right)\right)=\sum_{t=0}^{T} \sum_{i=0}^{N} \log \left\{b_{i}^{\prime}\left(o_{t}\right)\right\} \alpha(i, t) \beta(i, t)$.

$\tilde{Q}\left(\lambda, \lambda^{\prime}\right)$ を最大化する $\lambda^{\prime}$ を求めるためには，(24)(25)(26) 式の $\tilde{Q}_{1}\left(\lambda, \pi_{i}^{\prime}\right), \tilde{Q}_{2}\left(\lambda, a_{i j}^{\prime}\right), \tilde{Q}_{3}\left(\lambda,\left(\boldsymbol{\theta}_{i}^{\prime}, \sigma_{i}^{\prime}\right)\right)$ をそれぞれ最大 化する $\lambda^{\prime}$ を求めればよい.

$\tilde{Q}_{1}\left(\lambda, \pi_{i}^{\prime}\right), \tilde{Q}_{2}\left(\lambda, a_{i j}^{\prime}\right), \tilde{Q}_{3}\left(\lambda,\left(\boldsymbol{\theta}_{i}^{\prime}, \sigma_{i}^{\prime}\right)\right)$ をそれぞれ最大化す る $\lambda^{\prime}$ を計算すると, つぎのように求められる。

$$
\begin{aligned}
\pi_{i}^{\prime} & =\frac{\pi_{i} b_{i}\left(o_{0}\right) \beta(i, 0)}{\sum_{k=0}^{N} \pi_{k} b_{k}\left(o_{0}\right) \beta(k, 0)}, \\
a_{i j}^{\prime}= & \frac{\sum_{t=1}^{T} \alpha(i, t-1) a_{i j} b_{j}\left(o_{t}\right) \beta(j, t)}{\sum_{k=0}^{N} \sum_{t=1}^{T} \alpha(i, t-1) a_{i k} b_{k}\left(o_{t}\right) \beta(k, t)} \\
\boldsymbol{\theta}_{i}^{\prime}= & \left\{\sum_{t=0}^{T}\left\{\boldsymbol{\psi}_{t} \boldsymbol{\psi}_{t}^{T} \alpha(i, t) \beta(i, t)\right\}\right\}^{-1} \\
& \times\left\{\sum_{t=0}^{T}\left\{\boldsymbol{\psi}_{t} y_{t} \alpha(i, t) \beta(i, t)\right\}\right\} \\
\sigma_{i}^{\prime 2}= & \frac{\sum_{t=0}^{T}\left\{\left|\boldsymbol{\psi}_{t}^{T} \boldsymbol{\theta}_{i}^{\prime}-y_{t}\right|^{2} \alpha(i, t) \beta(i, t)\right\}}{\sum_{t=0}^{T}\{\alpha(i, t) \beta(i, t)\}}
\end{aligned}
$$

(29)(30) 式の導出過程は付録 A に示す。(27)(28) 式に関し ては，通常の HMM と同じであるため，導出過程は省略す る。詳細は文献 ${ }^{8)}$ を参照されたい.

(27)(28)(29)(30) 式を用いて, EM アルゴリズムににおけ る 3 つのステップを繰り返すことにより, 逐次的にパラメー 夕 $\lambda$ を求めることが出来る. 


\section{$4.3 \boldsymbol{\theta}_{i}^{\prime}$ の重みつき最小二乗解としての解釈}

(29) 式は, 時刻 $t$ において状態 $S_{i}$ に滞在する確率である $\alpha(i, t) \beta(i, t)$ を重みとした, 重みつき最小二乗問題の解と解 釈することが出来る．以下ではその説明を行なう．

まず, $y_{t}, \boldsymbol{\psi}_{t}, e_{i, t}$ のベクトル表現を，つぎのように定義 する.

$$
\begin{aligned}
\boldsymbol{Y}_{T} & =\left(y_{0}, y_{1}, \cdots, y_{t}, \cdots, y_{T}\right)^{T} \in \boldsymbol{R}^{T+1} \\
\boldsymbol{\Psi}_{T} & =\left(\boldsymbol{\psi}_{0}, \boldsymbol{\psi}_{1}, \cdots, \boldsymbol{\psi}_{t}, \cdots, \boldsymbol{\psi}_{T}\right) \in \boldsymbol{R}^{(T+1) \times m} \\
\boldsymbol{E}_{i, t} & =\left(e_{i, 0}, e_{i, 1}, \cdots, e_{i, t}, \cdots, e_{i, T}\right)^{T} \in \boldsymbol{R}^{T+1}
\end{aligned}
$$

そして, 対角成分を $\alpha(i, t) \beta(i, t) （$ ただし $t=0,1, \cdots, T$ ) とし, そのほかの成分は 0 としたつぎのような行列 $Z_{i, T}$ を 定義する.

$$
\boldsymbol{Z}_{i, T}=\left[\begin{array}{cccc}
\alpha(i, 0) \beta(i, 0) & 0 & \cdots & \\
0 & \alpha(i, 1) \beta(i, 1) & 0 & \\
\vdots & 0 & \ddots & 0 \\
& & 0 & \alpha(i, T) \beta(i, T)
\end{array}\right]
$$

ここで, 前向き確率 $\alpha(i, t)$ は, 時刻 $t$ までに出力記号 系列 $\boldsymbol{O}=\left(o_{0}, o_{1}, \cdots, o_{t}\right)$ を出力して, 状態 $S_{i}$ に達する $\left(s_{t}=S_{i}\right.$ となる) 確率であり, 後ろ向き確率 $\beta(i, t)$ は, 時刻 $t$ で状態 $S_{i}$ から $\left(s_{t}=S_{i}\right.$ から), 出力記号系列 $\boldsymbol{O}=\left(o_{t+1}, o_{t+2}, \cdots, o_{T}\right)$ を出力して, 最終状態に達する確 率であったから， $\alpha(i, t) \beta(i, t)$ は, Fig. 4 のように, 特定の 出力シンボル系列 $\boldsymbol{O}=\left(o_{0}, o_{1}, \cdots, o_{t}, \cdots, o_{T}\right)$ を出力する とき, 時刻 $t$ で離散状態 $S_{i}$ に滞在する確率を表わしている.

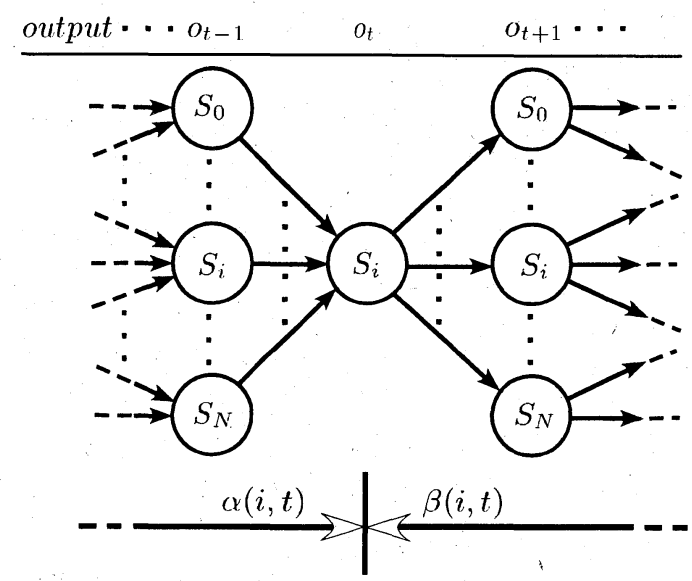

Fig. $4 \quad \alpha(i, t)$ and $\beta(i, t)$

今, SS-ARX モデルによる推定式である(29) 式を， (31)(32)(33)(34) 式によって表わすと，

$$
\boldsymbol{\theta}_{i}^{\prime}=\left\{\boldsymbol{\Psi}_{T} \boldsymbol{Z}_{i, T} \boldsymbol{\Psi}_{T}^{T}\right\}^{-1} \boldsymbol{\Psi}_{T} \boldsymbol{Z}_{i, T} \boldsymbol{Y}_{T}
$$

一方, 各離散状態 $S_{i}$ での ARX モデルのパラメータを, (31)(32)(33) 式を用いて書き換えると, つぎのようになる.

$$
\boldsymbol{Y}_{T}=\boldsymbol{\Psi}_{T}^{T} \boldsymbol{\theta}_{i}+\boldsymbol{E}_{i, t} .
$$

ここで, $\boldsymbol{W}_{i, T}^{T} \boldsymbol{W}_{i, T}=\boldsymbol{Z}_{i, T}$ となるような $\boldsymbol{W}_{i, T}$ で重み 付けされた，式誤差ベクトル $\boldsymbol{E}_{i, t}$ を最小にする最小二乗問 題を考える:この重み付けされた最小二乗問題の解は,

$$
\begin{aligned}
\arg \min _{\boldsymbol{\theta}_{i}}\left\|\boldsymbol{W}_{i, T}\left(\boldsymbol{\Psi}_{T}^{T} \boldsymbol{\theta}_{i}-\boldsymbol{Y}_{T}\right)\right\| \\
=\left\{\boldsymbol{\Psi}_{T} \boldsymbol{W}_{i, T}^{T} \boldsymbol{W}_{i, T} \boldsymbol{\Psi}_{T}^{T}\right\}^{-1} \boldsymbol{\Psi}_{T} \boldsymbol{W}_{i, T}^{T} \boldsymbol{W}_{i, T} \boldsymbol{Y}_{T} \\
=\left\{\boldsymbol{\Psi}_{T} \boldsymbol{Z}_{i, T} \boldsymbol{\Psi}_{T}^{T}\right\}^{-1} \boldsymbol{\Psi}_{T} \boldsymbol{Z}_{i, T} \boldsymbol{Y}_{T}
\end{aligned}
$$

となる。

以上より, SS-ARX モデルにおける推定式 $\boldsymbol{\theta}_{i}^{\prime}$ は, 時刻 $t$ で離散状態 $S_{i}$ に滞在する確率で重み付けされた最小二乗問 題の解として解釈することが出来る.

\section{5. 切り替え型インピーダンスモデルへの適用例}

ここでは, 同定対象として時間と共にインピーダンスが離 散的に切り替わる機械インピーダンスモデルを考え，提案す るパラメータ推定法の有用性を検証する。そして入出力デー 夕と推定されたパラメータを用いて, Viterbiアルゴリズム により切り替え時刻の推定を行なう例を示す.

\section{1 同定対象}

同定対象は, Fig. 5 のような, ばね, マス, ダンパから なる機械インピーダンスモデルとする．物体への力を入力 $u(t)$ とし, 物体の変位を出力 $y(t)$ とする. 各パラメー夕は Table 1 のように決め, 時刻 $t_{1}=2.0(\mathrm{~s})$ でばね定数が $K_{0}$ から $K_{1}$ に, 時刻 $t_{2}=7.0(\mathrm{~s})$ でばね定数が $K_{1}$ から $K_{2}$ に切り替わるインピーダンスモデルとした。

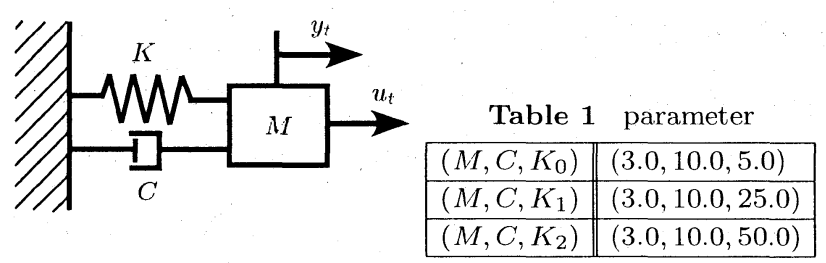

Fig. 5 Impedance model

\section{2 近似離散時間モデルによる同定対象の表現}

Fig. 5 の機械インピーダンスモデルは,

$$
Y(s)=\frac{1}{M s^{2}+C s+K_{i}} U(s)
$$

と, 表わすことが出来る. ただし, $Y(s), U(s)$ は, $y(t), u(t)$ のラプラス変換である．以下ではこのモデルに対して，連続 時間系のパラメータを保存した近似離散時間モデル 9) を導き， その差分方程式に，今回提案したSS-ARX モデルを適用する こととする. まず, $(38)$ 式の, 伝達関数 $G(s)=Y(s) / U(s)$

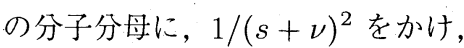

$$
Y(s)=\frac{\frac{1}{(s+\nu)^{2}}}{\frac{M s^{2}+C s+K_{i}}{(s+\nu)^{2}}} U(s)
$$


とする $(i=0,1,2)$.これは, ローパス・フィル夕による処 理を行なうことに相当する。 そして, $s=\frac{2}{\Delta} \frac{1-z^{-1}}{1+z^{-1}}$ として ( $\Delta$ はサンプリング周期) 双一次変換を行なうことで (39) 式は,

$$
U_{F}(z)=M Y_{F 0}(z)+C Y_{F 1}(z)+K_{i} Y_{F 2}(z)
$$

となる。ただし，(40) 式において，

$$
\begin{aligned}
U_{F}(z) & =\frac{\left(\frac{\Delta}{2}\right)^{2}\left(1+z^{-1}\right)^{2}}{\left\{\left(1+\nu \frac{\Delta}{2}\right)-\left(1-\nu \frac{\Delta}{2}\right) z^{-1}\right\}^{2}} U(z), \\
Y_{F k}(z) & =\frac{\left(\frac{\Delta}{2}\right)^{k}\left(1+z^{-1}\right)^{k}\left(1-z^{-1}\right)^{2-k}}{\left\{\left(1+\nu \frac{\Delta}{2}\right)-\left(1-\nu \frac{\Delta}{2}\right) z^{-1}\right\}^{2}} Y(z)
\end{aligned}
$$

である $(k=0,1,2)$. (40) 式を逆 $z$ 変換し, 式誤差 $e_{i, t}$ を 加えると，

$$
\begin{aligned}
& u_{F t}=M y_{F 0, t}+C y_{F 1, t}+K_{i} y_{F 2, t}+e_{i, t}, \\
& u_{F t}=\boldsymbol{\psi}_{t}^{T} \boldsymbol{\theta}_{i}+e_{i, t}
\end{aligned}
$$

と表わすことが出来る.ただし $u_{F, t}, y_{F k, t}$ は, $U_{F}(z), Y_{F k}(z)$ を逆 $z$ 変換して得られた值であり, (41)(42) 式より, 同定 対象から測定する入力 $u(t)$ および出力 $y(t)$ から求めるこ とが出来る.

(43)(44) 式では, 連続時間系パラメータが陽に式中に現れ ている。よって, 4 節のパラメー夕推定により, 式誤差 $e_{i, t}$ を最小にする連続時間系パラメー夕 $\boldsymbol{\theta}_{i}=\left(M, C, K_{i}\right)$ を直 接推定することが出来る.

\section{3 同定モデル}

同定用の SS-ARX モデルとしては, Fig.6 のような leftto-right 型のモデルを用いる。なお，状態数 $N$ は 3 とした。 また，各離散状態 $S_{i}$ における近似離散モデルを，

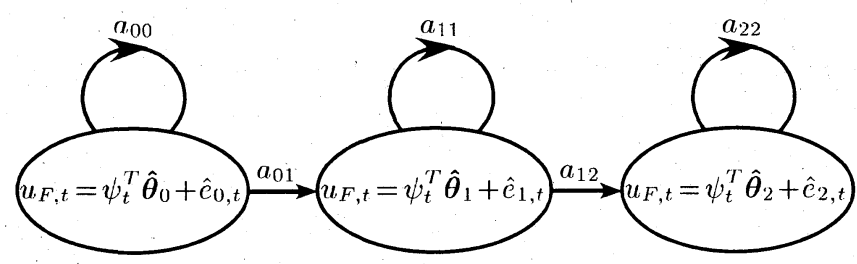

Fig. 6 SS-ARX Model (left-to-right)

$$
\begin{aligned}
& u_{F t}=\hat{M} y_{F 0, t}+\hat{C} y_{F 1, t}+\hat{K}_{i} y_{F 2, t}+\hat{e}_{i, t} \\
& u_{F t}=\boldsymbol{\psi}_{t}^{T} \hat{\boldsymbol{\theta}}_{i}+\hat{e}_{i, t}
\end{aligned}
$$

とする. Fig.6のような left-to-right 型のモデルは, HMM による音声認識で一般に用いられるモデルである。

\section{4 式誤差 $e_{i, t}$ が 0 の場合の検証および考察}

サンプリング時間 $\Delta=0.05(\mathrm{~s})$ として, SS-ARX モデル における $a_{i j}, \sigma_{i}$ および，機械インピーダンスモデルのパラ メー夕 $\boldsymbol{\theta}_{i}=\left(M, C, K_{i}\right)$ を推定した。ただし, (43)(44) 式 における式誤差 $e_{i, t}$ の分散 $\sigma_{i}$ の真值は 0.0 とし，入力 $u(t)$ には $\mathrm{M}$ 系列信号を用いた。 また，近似離散モデルにおける $\nu$ は, 試行錯誤的に今回は $\nu=5.0$ とした。
推定したパラメータ $\left(\hat{M}, \hat{C}, \hat{K}_{i}\right)$, 式誤差 $\hat{e}_{i, t}$ の分散 $\hat{\sigma}_{i}$, および Viterbi アルゴリズムで推定した切り替え点 $\left(\hat{t}_{1}, \hat{t}_{2}\right)$ を Table 2 に示す。これを見ると，ほぼ各パラメータが正 しく推定できていることがわかる．

なお，Viterbiアルゴリズムでは $(47)$ 式に従って，まず， 各時間 $t$ で離散状態 $S_{i}$ において一つ前の時間 $t-1$ から到 達し, かつ与えられた出力シンボル系列を出力する確率のう ち，最大の確率 $\delta(i, t)$ を求める。そして (48) 式のように, 時刻 $t-1$ での離散状態 $S_{j}$ 求め, $\gamma(i, t)$ とする. 最終時刻 $T$ まで $\delta(i, t), \gamma(i, t)$ を求め, その後, $\gamma(i, t)$ を時刻 $T$ か ら時刻 0 まで順に追えば，一番もっともらしい状態遷移系 列を得る。

$$
\begin{aligned}
& \delta(i, t)=\max _{0 \leq j \leq N}\left\{\delta(j, t-1) a_{j i} b_{i}\left(o_{t}\right)\right\}, \\
& \gamma(i, t)=\underset{0 \leq j \leq N}{\arg \max }\left\{\delta(j, t-1) a_{j i} b_{i}\left(o_{t}\right)\right\} .
\end{aligned}
$$

つぎに，推定したパラメータと切り替え点を用いて，Fig. 5 のような機械インピーダンスモデルを構成し, Fig. 5, Table 1 に示す同定対象の機械インピーダンスモデルと比較した。推 定に用いた入力と同じ入力を加えたときの比較を，Fig. 7 に示す.

Table 2 Identified model

\begin{tabular}{|c||l|}
\hline$\left(\hat{M}, \hat{C}, \hat{K}_{0}\right)$ & $(3.280515,9.143437,6.766880)$ \\
\hline$\left(\hat{M}, \hat{C}, \hat{K}_{1}\right)$ & $(3.100449,9.405431,23.845222)$ \\
\hline$\left(\hat{M}, \hat{C}, \hat{K}_{2}\right)$ & $(3.123556,10.604624,49.874892)$ \\
\hline$\left(\hat{\sigma}_{0}, \hat{\sigma}_{1}, \hat{\sigma}_{2}\right)$ & $(0.001080,0.000904,0.000793)$ \\
\hline \hline$\left(\hat{t}_{1}, \hat{t}_{2}\right)$ & $(2.55,7.45)$ \\
\hline
\end{tabular}

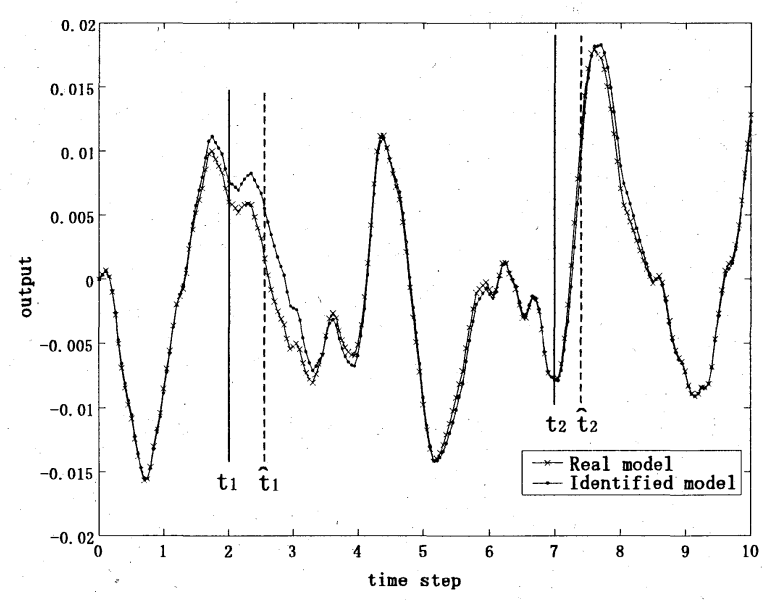

Fig. 7 Real model and Identified model

Fig. 7 より，切り替え点付近で両者に差異が見られるもの の，ほほ現象を再現できていることがわかる。

各離散状態に割り当てた ARX モデルは，過去の時間の入 出力により現在の時間の出力を導く差分方程式であるので, 
切り替え点付近は前の離散状態の入出力を用いていること になる，そのため切り替え点付近においては，両者の間にず れが生じたと考えられる。

\section{5 式誝差 $e_{i, t}$ を与えた場合の検証および考察}

5.4 節では, (43)(44) 式における式誤差 $e_{i, t}$ を, 0.0 と して推定を行なった。ここでは，式誤差 $e_{i, t}$ の分散 $\sigma_{i}$ を; $\sigma_{0}=0.005, \sigma_{1}=0.003, \sigma_{2}=0.001$ として推定を行なう.

推定したパラメータ $\left(\hat{M}, \hat{C}, \hat{K}_{i}\right)$, 式䛊差 $\hat{e}_{i, t}$ の分散 $\hat{\sigma}_{i}$, および Viterbi アルゴリズムで推定した切り替え点 $\left(\hat{t}_{1}, \hat{t}_{2}\right)$ を Table 3 に示す。これを見ると，式誤差の分散が大きい 離散状態では，パラメータの精度があまりよくないが，ほほ 各パラメータを推定できていることがわかる.

つぎに，推定したパラメータと切り替え点を用いて，Fig. 5 のような機械インピーダンスモデルを構成し, Fig. 5, Table 1 に示す同定対象の機械インピーダンスモデルと比較した. 推 定に用いた入力と同じ入力を加えたときの比較を, Fig. 8 に示す.

Table 3 Identified model (with equation error)

\begin{tabular}{|c||l|}
\hline$\left(\hat{M}, \hat{C}, \hat{K}_{0}\right)$ & $(3.337358,9.762908,8.193043)$ \\
\hline$\left(\hat{M}, \hat{C}, \hat{K}_{1}\right)$ & $(3.184201,9.714739,26.112467)$ \\
\hline$\left(\hat{M}, \hat{C}, \hat{K}_{2}\right)$ & $(3.175045,10.661780,49.292384)$ \\
\hline$\left(\hat{\sigma}_{0}, \hat{\sigma}_{1}, \hat{\sigma}_{2}\right)$ & $(0.004291,0.002314,0.001472)$ \\
\hline \hline$\left(\hat{t}_{1}, \hat{t}_{2}\right)$ & $(2.7,7.45)$ \\
\hline
\end{tabular}

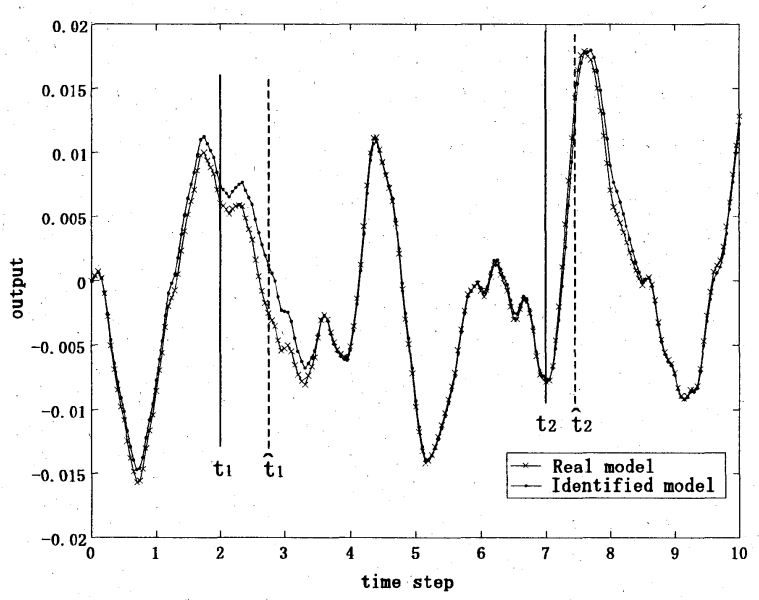

Fig. 8 Real model and Identified model (with equation error)

Fig. 8 より, 式誤差 $e_{i, t}$ が 0 の場合と同様に切り替え点 付近で両者に差異が見られるものの，ほぼ現象を再現できて いることがわかる.

\section{6 単一の ARX モデルを用いた場合との比較}

つぎに，同定対象をハイブリッドシステムとして同定する 有用性を示すため, サンプリング時間 $\Delta=0.05(\mathrm{~s})$ として,

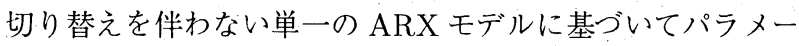

夕 $\boldsymbol{\theta}=(M, C, K)$ を推定した場合との比較を示す。ただし, (43)(44) 式における式誤差 $e_{i, t}$ の分散 $\sigma_{i}$ の真值は 0.0 とし た，また，近似離散モデルにおける $\nu$ は，5.4 節と同様に $\nu=5.0$ とした.

推定したパラメー夕 $(\hat{M}, \hat{C}, \hat{K})$ を Table 4 に示す。これ を見ると，切り替えていないパラメータ $M, C$ は，ほぼ推 定できているできているが，切り替えたパラメータKは， $K_{0}, K_{1}, K_{2}$ のほぼ平均值となっていることがわかる。

つぎに，推定したパラメータを用いて，Fig.5のような機 械インピーダンスモデルを構成し, Fig. 5 と Table 1 に示す 同定対象の機械インピーダンスモデルと比較した. 推定に用 いた入力と同じ入力を加えたときの比較を，Fig. 9 に示す. 切り替えを伴わない単一の ARX モデルを用いて最小二乗 推定した場合の平均二乗誤差は 0.004101438 で, SS-ARX モデルによる推定結果の平均二乗誤差は 0.000322878 で あった。

これらの数值例，および Fig. 7 と Fig. 9 の比較より, SSARX モデルのほうがより精度よく推定できていることがわ かる。

Table 4 Identified model (single ARX model) \begin{tabular}{|l||l|}
$(\hat{M}, \hat{C} ; \hat{K})$ & $(3.030606,9.656241,26.704166)$ \\
\hline
\end{tabular}

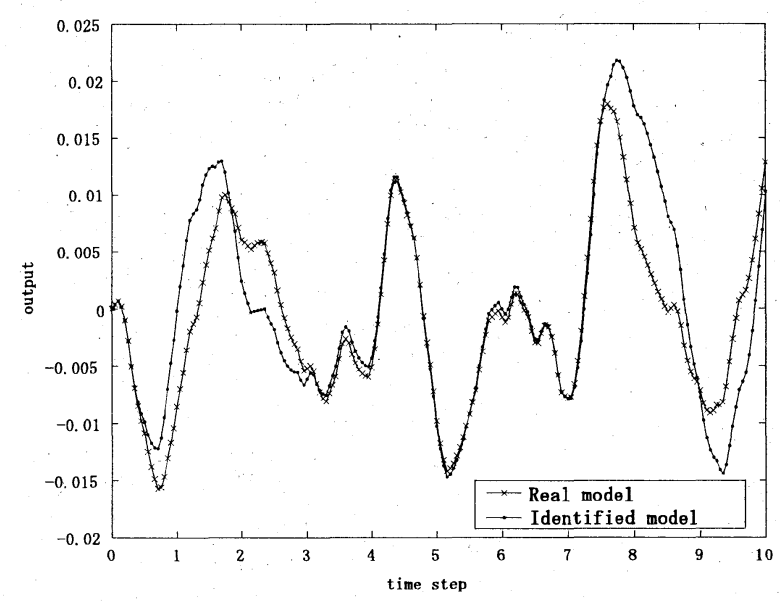

Fig. 9 Real model and Identified model (single ARX model)

\section{6. おわりに}

本論文では，確率的切り替えを伴う ARX モデルに対する

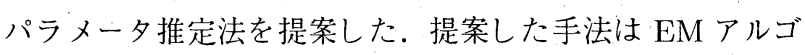
リズムをベースとしており，HMMに扔けるパラメー夕推定 法の自然な拡張となっている。また，提案手法を切り替えを 伴うインピーダンスモデルの推定に適応し，その有用性を検 証した，提案手法によって求められるパラメー夕は，探索の 初期に設定するパラメータに強く依存するため, データク 
ラスタリングなど，適切な初期パラメータの設定法および， 離散構造の決定法が今後の課題となる.

一方, 本論文で対象とした非定常時系列を扱う手法とし て, 局所定常 $\mathrm{AR}$ モデルや時変係数 $\mathrm{AR}$ モデルなどの手法 がある 10)，11). 局所定常 AR モデルは，各区間の時系列を AR モデルで表現したモデルで，AIC 規範に基づいて最適 な区間の分割を行なっている，時変係数 AR モデルでは，非 定常時系列を係数が時間と共に变化する自己回帰モデルで 表現している。これらの手法に入力項を加えることも可能で あるため，これらとの比較も必要であると思われる。

また，人間の行動解析やシステムバイオロジーへの適用を 応用面での検討課題としたい.

\section{参 考 文 献}

1) Lecture Notes in Computer Science; Hybrid Systems: Computation and Control, Springer (1999)

2) J.H.Kim, S.Hayakawa, T.Suzuki et.al: Modeling of Human Driving Behavior based on Expression as Hybrid Dynamical System, Trans.of SICE, 40-2, 180/188 (2004)

3) G.Ferrari-Trecate, M.Morari et.al: A clustering technique for the identification of piecewise affine systems, Automatica, 39, 205/217 (2003)

4) J.Roll, A.Bemporad, et.al: Identification of piecewise affine systems via mixed-integer programming, Automatica, 40, 37/50 (2004)

5) Lawrence R. Rabiner; A Tutorial on Hidden Markov Models and Selected Applications in Speech Recognition, IEEE, 77 (1989)

6) H.Balakrishnan et.al: Inference Methods for Autonomous Stochastic Linear Hybrid Systems LNCS2993, HSCC 2004, 64/79 (2004)

7) K.Itabashi, S.Yea, T.Suzuki and S.Okuma: Acquisition of Human Skill with Hidden Model, T.SICE, 34-8, August (1998)

8) 安藤榇男：リアルタイム咅声認識, 電子情報通信学会 (2003)

9）和田 清：連続時間システムのサンプル值デー夕による同定, J.SICE, 32-9, 712/717 (1993)

10）北川源四郎：FORTRAN77 時系列解析プログラミング, 岩波 書店 (1993)

11). 赤池, 北川：時系列解析の実際 I, 朝倉書店 (1994)

12）小林哲則:暚れマルコフモデルに基づく音声認識, 電学論 (1994)

13）足立修一：MATLABによる制御のためのシステム同定，東京 電機大学出版局 (1996)

\section{《付録》}

\section{A. 推定式 (29)(30) の導出}

(26) 式と, 各離散状態 $S_{i}$ に扔ける観測シンボル $o_{t}$ の生 起確率 $b_{i}\left(o_{t}\right)$ の定義式である (11) 式より, $\tilde{Q}_{3}\left(\lambda, \lambda^{\prime}\right)$ を最 大化するパラメータ $\lambda^{\prime}$ のうち, $b_{i}^{\prime}\left(o_{t}\right)$, つまり $\boldsymbol{\theta}_{i}^{\prime}, \sigma_{i}^{\prime}$ は,

$$
\begin{aligned}
& \frac{\partial \tilde{Q}_{3}}{\partial \boldsymbol{\theta}_{i}^{\prime}}=0 \\
& \frac{\partial \tilde{Q}_{3}}{\partial \sigma_{i}^{\prime}}=0
\end{aligned}
$$

として $\boldsymbol{\theta}_{i}^{\prime}$ と $\sigma_{i}^{\prime}$ を解けば求められる. $\theta_{i}^{\prime}$ については, (11) 式から，

$$
\log b_{i}^{\prime}\left(o_{t}\right)=-\log \left(\sqrt{2 \pi} \sigma_{i}^{\prime}\right)-\frac{1}{2 \sigma_{i}^{2}}\left(\psi_{t}^{T} \theta_{i}^{\prime}-y_{t}\right)^{2}(\mathrm{~A} .3)
$$

より，

$$
\begin{aligned}
\frac{\partial \tilde{Q}_{3}}{\partial \boldsymbol{\theta}_{i}^{\prime}} & =\frac{\partial}{\partial \boldsymbol{\theta}_{i}^{\prime}}\left\{\sum_{t=0}^{T} \sum_{i=0}^{N} \log \left\{b_{i}^{\prime}\left(o_{t}\right)\right\} \alpha(i, t) \beta(i, t)\right\} \\
& =\sum_{t=0}^{T} \frac{1}{\sigma_{i}^{2}} \psi_{t} \cdot\left(\boldsymbol{\psi}_{t}^{T} \boldsymbol{\theta}_{i}^{\prime}-y_{t}\right) \alpha(i, t) \beta(i, t) \\
& =0
\end{aligned}
$$

なので,

$$
\begin{aligned}
& \sum_{t=0}^{T} \frac{1}{\sigma_{i}^{2}}\left\{\boldsymbol{\psi}_{t} \boldsymbol{\psi}_{t}^{T} \boldsymbol{\theta}_{i}^{\prime} \alpha(i, t) \beta(i, t)\right. \\
&\left.-\boldsymbol{\psi}_{t} y_{t} \alpha(i, t) \beta(i, t)\right\}=0
\end{aligned}
$$

よって,

$$
\begin{aligned}
\boldsymbol{\theta}_{i}^{\prime}=\left\{\sum_{t=0}^{T}\left\{\boldsymbol{\psi}_{t} \boldsymbol{\psi}_{t}^{T} \alpha(i, t) \beta(i, t)\right\}\right\}^{-1} \\
\times\left\{\sum_{t=0}^{T}\left\{\psi_{t} y_{t} \alpha(i, t) \beta(i, t)\right\}\right\}
\end{aligned}
$$

と求められる.

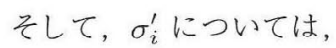

$$
\begin{aligned}
\frac{\partial \tilde{Q}_{3}}{\partial \sigma_{i}^{\prime}} & =\frac{\partial}{\partial \sigma_{i}^{\prime}}\left\{\sum_{t=0}^{T} \sum_{i=0}^{N} \log \left\{b_{i}^{\prime}\left(o_{t}\right)\right\} \alpha(i, t) \beta(i, l)\right\} \\
& =\sum_{t=0}^{T}\left\{\frac{1}{\sigma_{i}^{\prime}}+\frac{1}{\sigma_{i}^{\prime 3}}\left|\boldsymbol{\psi}_{t}^{T} \boldsymbol{\theta}_{i}^{\prime}-y_{t}\right|^{2}\right\} \alpha(i, t) \beta(i, t) \\
& =0
\end{aligned}
$$

よって,

$$
\sigma_{i}^{\prime 2}=\frac{\sum_{t=0}^{T}\left\{\left|\psi_{t}^{T} \boldsymbol{\theta}_{i}^{\prime}-y_{t}\right|^{2} \alpha(i, t) \beta(i, t)\right\}}{\sum_{t=0}^{T}\{\alpha(i, t) \beta(i, t)\}}
$$

と求められる.

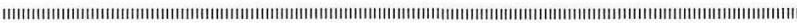

$$
\text { [著 者 紹 介] }
$$

\section{山田直幸}

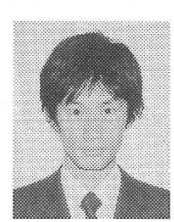

1981 年 6 月 15 日生. 2004 年名古屋大学工学 部機械航空工学科卒業. 同午, 同大学大学院工学 研究科機械理工学専攻修士課程進学, 現在に至る。 
鈴 木 達 也 (正会員)

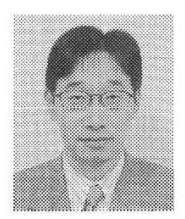

1964 年 1 月 3 日生. 91 年名古屋大学大学院 博士課程後期課程電子機械工学専攻修了. 工学 博士. 同年名古屋大学工学部助手. 2000 年同助 教授。現在に至る。この間, 98 年から 1 年間, U.C.Berkeley 客員研究崱. 知的なモーションコ ントロール，ハイブリッドシステム論とその実シ ステムへの応用に関する研究に従事. 95 年電気 学会論文賞, 2004 年 SICE システム情報部門学 術講演会論文賞などを受賞. 電気学会, 電子情報 通信学会, 日木機械学会, システム制御情報学会, 日本ロボット学会, 日本人間工学会, IEEEの各 会員.

稲 垣 伸 吉 (正会員)

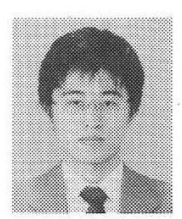

2000 年名古屋大学大学院電子機械工学科博士前 期課程修了. 同年, 東京大学大学院工学系研究科 博士課程入学. 2003 年名古屋大学大学院工学研究 科機械理工学専攻助手. 同年理化学研究所 BMC 非常勤研究員兼任. 現在に至る. 自律分散システ 厶, 歩行ロボット, 確率的情報処理の研究に従事. SICE, RSJ, JSMEの会員. 博士 (工学). 